\title{
Sexual Contact Patterns in High-income Countries - A Comparative Analysis Using Data From Germany, The UK, and The US
}

\section{Damilola Victoria Tomori}

Institute of Epidemiology and Social Medicine, University of Münster, Münster

Johannes Horn

Institute for Medical Epidemiology, Biostatistics and Informatics, University of Halle

Nicole Rübsamen

Institute of Epidemiology and Social Medicine, University of Münster, Münster

Sven Kleine Bardenhorst

Institute of Epidemiology and Social Medicine, University of Münster, Münster

Veronika K Jaeger

Institute of Epidemiology and Social Medicine, University of Münster, Münster

André Karch ( $\square$ Andre.Karch@ukmuenster.de)

Institute of Epidemiology and Social Medicine, University of Münster, Münster

\section{Rafael Mikolajczyk}

Institute for Medical Epidemiology, Biostatistics and Informatics, University of Halle

\section{Research Article}

Keywords: Contact patterns, sexual behaviour, mathematical model

Posted Date: February 19th, 2021

DOl: https://doi.org/10.21203/rs.3.rs-209394/v1

License: (c) (i) This work is licensed under a Creative Commons Attribution 4.0 International License. Read Full License 


\section{Abstract}

Sexual contact patterns determine the spread of sexually transmitted infections, and are a central input parameter for mathematical models in this field. We evaluated the importance of country-specific contact pattern parametrization for high-income countries with similar cultural backgrounds by deriving estimates for sexual contact patterns in Germany from two independent studies (HaBIDS and SBG), and comparing them to data from the National Survey of Sexual Attitudes and Lifestyles (Natsal) in the UK, and the National Survey of Family Growth (NSFG) in the US. UK and US participants reported a substantially higher number of lifetime opposite-sex sexual partners compared to both German studies. The difference in lifetime partners was caused by a higher proportion of individuals with many partners in the young age group ( $<24$ years) in the UK and the US. Partner acquisition in older age groups was similar. The number of same-sex partners was similar across the countries, while there was heterogeneity in the reported experience with partners from both sexes, consistent with the differences observed for opposite-sex sexual partners. These patterns can lead to substantially different dynamics of sexually transmitted infections across age, and have strong impact on the results of modelling studies.

\section{Introduction}

Sexually Transmitted Infections (STIs) are caused by over 30 different bacteria, viruses and parasites ${ }^{1}$, and are a major threat to global public health with more than 350 million curable STIs cases ${ }^{1}$ diagnosed each year. Behavioural factors associated with the number of sexual partners, the concurrency of sexual partnerships, and the use of preventive barrier devices like condoms are crucial for the transmission dynamics of STIs ${ }^{2}$. The so-called sexual contact patterns are subject to change, and can depend on cultural habits, religious beliefs, and societal norms ${ }^{2,3}$.

Several studies have assessed the relationship between sexual contact patterns and various sexually transmitted infections ${ }^{2,4-6}$, and were e.g. crucial in the understanding of the role of concurrent partnerships for the heterosexual spread of HIV in Sub-Saharan Africa ${ }^{6}$. Information about sexual contact patterns is important for the parametrization of mathematical models studying STIs transmission, which are used to guide prevention efforts. However, there is little systematic evidence for population-based estimates on the frequency of various types of sexual contact patterns in many geographic and cultural settings. The scarcity of research is often attributed to the fact that surveys on sexual contacts are generally sensitive and privy topics for discussion.

However, there are few large-scale projects like Natsal (National Survey of Sexual Attitudes and Lifestyles, Natsal $^{7}$ ) in the United Kingdom and NSFG in the United States (National Survey of Family Growth ${ }^{8,9}$ ), which provide long-term high-quality data for selected high-income countries. Sexual contact patterns reported in these two projects are commonly used for modelling STIs transmission in countries without systematic data collection, like e.g. Germany. The main objective of this study is to provide populationlevel estimates for sexual contact patterns in Germany, and to compare them to data obtained from Natsal and NSFG for the UK and US. 


\section{Methods}

\section{Data Source, Setting and Study Population}

This study uses data from the Hygiene and Behaviour Infectious Diseases Survey (HaBIDS) panel which included individuals from four counties in the Federal State of Lower Saxony, Germany (Braunschweig, Salzgitter, Vechta, and Wolfenbüttel) and was run between 2014 and $2017^{10}$. HaBIDS was designed to study knowledge, attitudes, and practice towards infectious diseases from various perspectives ${ }^{10-12}$. Potential participants aged between 15 and 69 years were selected from the population registries of the respective counties by proportional stratified random sampling, and were invited by mail to participate initially in a mixed method (paper-pencil and online) and later on in an online only panel. A series of questionnaires regarding behaviour in the context of infectious diseases including sexual contact behaviour was sent to all participants. Data on sexual contacts were collected using paper-based (in July 2014) and online-based questionnaires (in June 2015). Further details on the HaBIDS study and its methodology can be found in Rübsamen et $\mathrm{al}^{10}$. At the initial stage, the HaBIDS panel consisted of 2,379 individuals from a registration office sample of 26,895 ( $9 \%$ participation rate). At the time of data collection on sexual contact behaviour, 123 individuals had already resigned from HaBIDS, 740 individuals did not send back the questionnaire and 318 individuals either found the questionnaire too personal, returned an empty questionnaire, or gave no information on the number of sexual partners, so that 1,198 participants were left for this analysis.

In the questionnaire, participants were asked if they had a sexual contact ever in their life, at which age they had their first sexual contact, how many sexual partners (opposite- and same-sex) they had during their entire life, during the last 12 months and how many new sexual partners they had during the last 12 months. Moreover, participants were asked to report the age and sex of their last three sexual partners which we refer to as last/current partner, penultimate partner, and pre-penultimate partner. A translated English version and the original German version of the questionnaire can be found in the Supplementary File. HaBIDS was approved by the Ethics Committee of Hannover Medical School (No. 2021 - 2013), and by the Federal Commissioner for Data Protection and Freedom of Information in Germany. All participants provided written informed consent prior to study entry. Consent was obtained from a parent or guardian on behalf of any participants aged 18 or below. HaBIDS study was performed in accordance with relevant guidelines and regulations.

We compared HaBIDS data to sexual contact patterns from a recent nationwide survey on sexual behaviour in Germany (SBG) ${ }^{13}$ (Table 1). Sexual contact patterns (in contrast to other sexual behaviour data) from this survey were not published before but were provided to us by the SBG authors. SBG participants were aged between 14 and 99 years at data collection in 2016. The included households were identified by subdividing the regional areas using the random route method; potential participants were selected using the kish selection grid $^{13}$. 
Table 1

Basic information on HaBIDS, SBG, Natsal and NSFG

\begin{tabular}{|llll|}
\hline Study & Country & N (participants) & Age range (years) \\
\hline HaBIDS & Germany & 1,198 & 15 to 69 \\
\hline SBG & Germany & 2,096 & 14 to 99 \\
\hline Natsal & UK & 15,118 & 16 to 74 \\
\hline NSFG & USA & 22,457 & 15 to 44 \\
\hline
\end{tabular}

We also compared HaBIDS and SBG to two long-term projects from the UK (Natsal) ${ }^{7}$ and the US (NSFG) 8,9 (Table 1). Natsal data used in our analysis were collected between 2010 and 2012 (Natsal 3 wave). Natsal used a multistage, clustered and stratified probability sample design and enrolled participants between the ages of 16 and 74 years $^{7}$. Data used in this publication from the NSFG study were sampled in the 2006 to 2010 survey. NSFG included participants aged 15 to 44 years based on an independent, national probability sampling 8,14 . For all studies, individual anonymized primary data were provided and used for further analyses.

Sexual contact patterns were compared between the four studies; the questions to collect these data were similarly phrased across the studies. Data on the number of lifetime sexual partners were available in all four studies. Data on the number of sexual partners in the last 12 months were available for HaBIDS, Natsal, and NSFG; data on the number of new partners in the last 12 months were available for HaBIDS and Natsal. No data were available for NSFG participants above the age of 44 years.

Participants who reported at least one opposite-sex sexual partner and at least one same-sex sexual partner are referred to as participants with "both-sex experience".

\section{Data analysis}

Absolute and relative frequencies and medians/means were used for descriptive analyses. Differences in the distribution of reported number of opposite-sex partners, same-sex partners and both-sex partners were investigated using negative binomial regression adjusted for age and sex (as well as stratified by age). Local regression methods were used to visualize the relationship between the number of sexual partners and the corresponding age of participants in a smoothed way. All analyses were performed using R-3.6. $1^{15}$ with the packages ggplot $2^{16}$ and MASS ${ }^{17}$.

\section{Results}

\section{Characteristics of the samples}

Of the 1,198 HaBIDS participants included in this study, 748 were female (62\%) and 450 were male (38\%). The median age was 47 years (interquartile range [IQR] 35-57 years); 36 participants (3\%) were below the 
age of 20 years and 213 participants (18\%) were over 60 years old. SBG participants had a median age of 47 years (IQR 32-58), while it was 34 years (IQR 24-52) for Natsal participants and 28 years (IQR 2136) for NSFG participants. Further information on the study populations can be found in Table 1.

\section{Current partnership and age at sexual debut}

There were no relevant differences in sexual contact patterns between HaBIDS participants using a paperbased questionnaire and those using an online questionnaire when taking age, sex, and education into account (Supplementary Table S1). At the time of data collection, $83 \%$ of the participants had a sexual partner and $60 \%$ of those thought that this sexual relationship will also continue for at least three months. Thirty participants $(2.5 \% ; 20$ men, 10 women; median age 18, IQR 17-26) reported that they have never had a sexual contact in their lifetime.

Men were older at their sexual debut than women in HaBIDS (median ages 18 years vs 17 years; Table 2, Fig. 1) as well as in the other studies. Participants with a university qualification or university degree were generally older at sexual debut when compared to those without a university qualification (Fig. 1). Women reported more often a sexual relationship with older opposite sex partners while men reported frequently to be engaged in sexual relationships with younger opposite sex partners (Fig. 2). 
Table 2

Demographic and sexual behaviour of the HaBIDS participants (IQR; interquartile range)

\begin{tabular}{|c|c|c|c|c|c|c|}
\hline & \multicolumn{2}{|c|}{ Men $(N=450)$} & \multicolumn{2}{|c|}{ Women $(\mathrm{N}=748)$} & \multicolumn{2}{|c|}{ Total $(N=1,198)$} \\
\hline & $\mathbf{N}$ & $\begin{array}{l}\text { Median } \\
\text { [IQR] }\end{array}$ & $\mathbf{N}$ & $\begin{array}{l}\text { Median } \\
\text { [IQR] }\end{array}$ & $\mathbf{N}$ & $\begin{array}{l}\text { Median } \\
\text { [IQR] }\end{array}$ \\
\hline Age of participants (in years) & 449 & $\begin{array}{l}49[36- \\
59]\end{array}$ & 748 & $\begin{array}{l}46[35- \\
55]\end{array}$ & 1197 & $\begin{array}{l}47[35- \\
57]\end{array}$ \\
\hline \multirow[t]{2}{*}{$\begin{array}{l}\text { Age of participants sexual debut (in } \\
\text { years) }\end{array}$} & 417 & $\begin{array}{l}18[17- \\
20]\end{array}$ & 726 & $\begin{array}{l}17[16- \\
19]\end{array}$ & 1143 & $\begin{array}{l}18[16- \\
19]\end{array}$ \\
\hline & $\mathbf{N}$ & $\%$ & $\mathbf{N}$ & $\%$ & $\mathbf{N}$ & $\%$ \\
\hline \multicolumn{7}{|l|}{ Marital status } \\
\hline Married & 263 & 60 & 445 & 61 & 708 & 61 \\
\hline Single & 138 & 32 & 194 & 27 & 332 & 28 \\
\hline Divorced & 32 & 7 & 68 & 9 & 100 & 8 \\
\hline Widowed & 5 & 1 & 25 & 3 & 30 & 3 \\
\hline \multicolumn{7}{|l|}{ Highest completed educational level } \\
\hline University degree & 213 & 48 & 274 & 37 & 487 & 42 \\
\hline University entrance qualification & 123 & 28 & 195 & 27 & 318 & 27 \\
\hline Lower secondary education or & 92 & 21 & 253 & 35 & 345 & 29 \\
\hline \multicolumn{7}{|l|}{ Apprenticeship } \\
\hline Still student & 11 & 3 & 10 & 1 & 21 & 2 \\
\hline \multicolumn{7}{|l|}{ Do you currently have a sexual partner? } \\
\hline Yes & 361 & 85 & 594 & 82 & 955 & 83 \\
\hline No & 64 & 15 & 134 & 18 & 198 & 17 \\
\hline \multicolumn{7}{|c|}{ Do you think this sexual relationship will continue in 3 months? } \\
\hline Yes & 245 & 97 & 328 & 99 & 573 & 97 \\
\hline No & 3 & 1 & 0 & 0 & 3 & 1 \\
\hline I don't know & 6 & 2 & 3 & 1 & 9 & 2 \\
\hline \multicolumn{7}{|c|}{ Did your partner have sexual intercourse with other people in the last 12 months? } \\
\hline Yes (I know that exactly) & 12 & 3 & 20 & 3 & 32 & 3 \\
\hline Yes (I suppose, but I'm not sure) & 6 & 2 & 11 & 2 & 17 & 2 \\
\hline
\end{tabular}




\begin{tabular}{|c|c|c|c|c|c|c|}
\hline \multirow[b]{2}{*}{ Yes } & \multicolumn{2}{|c|}{ Men $(N=450)$} & \multicolumn{2}{|c|}{ Women $(\mathrm{N}=748)$} & \multicolumn{2}{|c|}{ Total $(\mathrm{N}=1,198)$} \\
\hline & 9 & 2 & 15 & 2 & 24 & 2 \\
\hline No & 323 & 80 & 580 & 85 & 903 & 83 \\
\hline I do not know & 54 & 13 & 55 & 8 & 109 & 10 \\
\hline \multicolumn{7}{|c|}{ Do you know how many sexual partners your partner had in his/her life in total excluding yourself? } \\
\hline Yes, I can give an estimate & 139 & 36 & 258 & 40 & 397 & 39 \\
\hline I do not know & 245 & 64 & 388 & 60 & 633 & 61 \\
\hline \multicolumn{7}{|c|}{ How often did your partner use condoms in the past partnerships in his/her life? } \\
\hline Always (every intercourse) & 28 & 7 & 41 & 6 & 69 & 7 \\
\hline Sometimes & 54 & 14 & 160 & 25 & 214 & 21 \\
\hline Never & 30 & 8 & 50 & 8 & 80 & 8 \\
\hline I do not know & 268 & 71 & 396 & 61 & 664 & 64 \\
\hline \multicolumn{7}{|c|}{ In the last 12 months, how often did you use condoms with your last or current partners? } \\
\hline Always (every intercourse) & 46 & 12 & 71 & 12 & 117 & 12 \\
\hline Sometimes & 55 & 15 & 93 & 15 & 148 & 15 \\
\hline Never & 271 & 73 & 451 & 73 & 722 & 73 \\
\hline \multicolumn{7}{|c|}{ In the last 12 months, how often did you use condoms with your penultimate partners? } \\
\hline Always (every intercourse) & 16 & 30 & 24 & 33 & 40 & 31 \\
\hline Sometimes & 8 & 15 & 17 & 23 & 25 & 20 \\
\hline Never & 30 & 55 & 32 & 44 & 62 & 49 \\
\hline \multicolumn{7}{|c|}{ In the last 12 months, how often did you use condoms with your pre - penultimate partners? } \\
\hline Always (every intercourse) & 14 & 36 & 11 & 34 & 25 & 35 \\
\hline Sometimes & 8 & 20 & 5 & 16 & 13 & 18 \\
\hline Never & 17 & 44 & 16 & 50 & 33 & 47 \\
\hline
\end{tabular}

\section{Lifetime opposite-sex partners}

In HaBIDS, men and women had a median of 4 (IQR 2-8, and 2-7, respectively) lifetime opposite-sex sexual partners. In the group of 15 to 19 years old participants, 17 participants (46\%) reported to have never had an opposite-sex sexual partner; this proportion decreased strongly for older age groups. Fortythree percent of women and $13 \%$ of men reported to have had just a single partner in their entire life. Men had lower numbers of lifetime opposite-sex sexual partners in the younger age groups, and higher 
numbers in older age groups compared to women (Fig. 3a). Apart from the younger age groups (below 25 years for women and 30 years for men), the proportions of both men and women with a given number of lifetime partners were stable across age.

The number of reported lifetime partners was highest in Natsal followed by NSFG and both German studies (Fig. 4a, left panel, Table 3). The difference in lifetime partners can be linked to differences in the number of partners in younger age groups (14-24 years), while in the older age groups the age-related increase in the number of partners was similar. Consequently, the acquisition of new partners (partners in the last 12 months) differed more in younger age groups across countries (Fig. 4a, right panel). These patterns were generally similar in men and women, although absolute numbers of partners were consistently higher in men. The higher acquisition rate of new partners was not evenly distributed across all participants but caused by a higher proportion of persons in the groups with the highest partner changes (10-19, 20-29, 30 or more) in Natsal and, to a lesser extent, in NSFG (Fig. 4c). Those who reported more lifetime sexual partners had also more sexual partners in the last 12 months, supporting individual stability of behaviour as used in the concept of stable sexual activity groups (Fig. 4b).

Table 3: Comparison of the number of sexual partners between studies adjusted for age and sex. HaBIDS serves as the reference study.

\begin{tabular}{|c|c|c|c|}
\hline IRR (95\% Cl; negative binomial regression) & SBG & NSFG & Natsal \\
\hline Lifetime opposite-sex partners & $\begin{array}{l}1.16(1.06 \\
1.27)\end{array}$ & $\begin{array}{l}1.53(1.42 \\
1.64)\end{array}$ & $\begin{array}{l}1.76(1.63, \\
1.89)\end{array}$ \\
\hline Opposite-sex partners in the last 12 months & - & $\begin{array}{l}0.94(0.88 \\
1.01)\end{array}$ & $\begin{array}{l}1.04(0.97 \\
1.11)\end{array}$ \\
\hline New opposite-sex partners in the last 12 months & - & - & $\begin{array}{l}1.36(1.14 \\
1.62)\end{array}$ \\
\hline Lifetime same-sex partners & $\begin{array}{l}1.32(0.87 \\
1.98)\end{array}$ & $\begin{array}{l}0.81(0.57 \\
1.13)\end{array}$ & $\begin{array}{l}1.16(0.81 \\
1.60)\end{array}$ \\
\hline $\begin{array}{l}\text { Lifetime same-sex partners (at least one same-sex } \\
\text { partner) }\end{array}$ & $\begin{array}{l}1.70(1.30- \\
2.22)\end{array}$ & $\begin{array}{l}1.02(0.82- \\
1.26)\end{array}$ & $\begin{array}{l}1.91(1.53 \\
2.37)\end{array}$ \\
\hline Same-sex partners in the last 12 months & - & $\begin{array}{l}0.61(0.43 \\
0.87)\end{array}$ & $\begin{array}{l}0.90(0.63 \\
1.29)\end{array}$ \\
\hline New same-sex partners in the last 12 months & & - & $\begin{array}{l}1.38(0.73 \\
2.54)\end{array}$ \\
\hline Both-sex sexual partners in the entire life & $\begin{array}{l}2.31(1.83 \\
2.92)\end{array}$ & $\begin{array}{l}2.01(1.67 \\
2.40)\end{array}$ & $\begin{array}{l}2.81(2.33 \\
3.37)\end{array}$ \\
\hline Both-sex sexual partners in the last 12 months & - & $\begin{array}{l}0.86(0.69 \\
1.06)\end{array}$ & $\begin{array}{l}1.12(0.90, \\
1.39)\end{array}$ \\
\hline $\begin{array}{l}\text { New sexual partners (both-sex) in the last } 12 \\
\text { months }\end{array}$ & - & & $\begin{array}{l}1.66(1.00, \\
2.67)\end{array}$ \\
\hline
\end{tabular}


Note: Opposite/same/both-sex partners in the last 12 months are based on participants who had at least one lifetime opposite/same/both-sex sexual partner. New opposite/same/both-sex sexual partners in the last 12 months are based on participants who had at least one opposite/same/both-sex sexual partner in the last 12 months.

$\mathrm{Cl}$, confidence interval; IRR, incidence rate ratio; $\mathrm{OR}$, odds ratio

\section{Opposite-sex partners in the last 12 months}

Among HaBIDS participants who had at least one lifetime opposite-sex sexual partner, $14 \%$ reported to have had no opposite-sex sexual partner in the last 12 months, while $79 \%$ reported one and $7 \%$ reported two or more opposite-sex sexual partners in the last 12 months. In the 15 to 19 years old HaBIDS participants, among those with at least one lifetime opposite-sex partner, all women had at least one opposite-sex partner, whereas $25 \%$ of men had no opposite-sex sexual partner in the last 12 months (Fig. 3b). While there was no evidence for overall differences between HaBIDS, NSFG (IRR 0.94, 95\% Cl 0.88-1.01) and Natsal participants (IRR $1.04,95 \% \mathrm{Cl} 0.97-1.11$ ) (Table 3, Supplementary Table S3, Figure S4b), Natsal participants in the age group 15 to 24 years showed a higher number of opposite-sex sexual partner in the last 12 months (IRR $1.29,95 \% \mathrm{Cl} 1.03-1.63$ ) consistent with the analysis on lifetime partners. This was not true for NSFG (IRR $1.06,95 \% \mathrm{Cl} 0.85-1.33$ ) participants.

\section{New opposite-sex partners in the last 12 months}

Of those participants in HaBIDS with at least one opposite-sex sexual partner in the last 12 months, only $19 \%$ reported one or more new opposite-sex sexual partners in the last 12 months. The highest proportion of participants who reported a new opposite-sex sexual partner occurred in the age group 15 to 19 years (88\%) (Fig. 3c). Natsal reported a slightly higher number of new opposite-sex sexual partners (IRR 1.36, $95 \% \mathrm{Cl} 1.14-1.62$ ) among those who had at least one lifetime partner compared to HaBIDS (Table 3 , Supplementary Table S4, Figure S4b).

\section{Same-sex partners during lifetime and in the last 12 months}

Within HaBIDS, 121 participants (11\%; 38 men, 83 women) reported at least one same-sex sexual partner in their lifetime (in addition to potential opposite-sex sexual partners). Among participants who reported at least one same-sex sexual partnership, HaBIDS participants had a median of 2 lifetime same-sex partners (IQR 1-4). The number of partners was similar in NSFG (IRR 1.02, 95\% Cl 0.82-1.26) but higher in SBG (IRR 1.70, 95\% Cl 1.30-2.22) and Natsal (IRR 1.91, 95\%Cl 1.54-2.38; Fig. 5; Table 3).

Fifty percent of HaBIDS participants with at least one lifetime same-sex sexual partner, reported one or more same-sex sexual partner in the last 12 months (Supplementary Table S6). NSFG participants reported lower numbers of same-sex sexual partners in the last 12 months compared to HaBIDS (IRR $0.61,95 \% \mathrm{Cl} 0.43-0.87$ ); this was not the case for Natsal (IRR $0.90,95 \% \mathrm{Cl} 0.63-1.29)$. The number of new same-sex partners among those participants with a same-sex sexual partner in the past 12 months did not differ between Natsal and HaBIDS (IRR 1.38, 95\% Cl 0.73-2.54; Table 3; Supplementary Table S7). 


\section{Participants with both-sex sexual experience during lifetime and in the last 12 months}

One hundred and thirteen (9\%) of the HaBIDS participants reported to have had at least one opposite- and one same-sex sexual partner at some point during their lives. This percentage was similar in NSFG $(10 \%$; OR $1.05,95 \% \mathrm{Cl} 0.86-1.30)$, but considerably lower in SBG $(6 \%$; OR $0.62,95 \% \mathrm{Cl} 0.48-0.82)$ and Natsal $(5 \%, \mathrm{OR} 0.53,95 \% \mathrm{Cl} 0.43-0.66)$. Among those participants with both-sex sexual experience, HaBIDS participants reported to have had a median of seven lifetime partners (IQR 4-11; Supplementary Table S8). The number of lifetime partners was higher in the other three studies (NSFG IRR 2.01, 95\% Cl 1.672.40; SBG IRR 2.31, 95\% Cl 1.83-2.92; Natsal IRR 2.81, 95\% Cl 2.33-3.37; Table 3)

\section{Discussion}

In this manuscript we provide for the first time systematically collected data on sexual contact patterns in the German population from two independent studies; these data can be used for the parametrization of mathematical models in the field of sexually transmissible infections. Our analysis found that sexual contact patterns in Germany were similar to those reported from the UK and US. However, there were important differences with respect to the proportion of participants with a high number of partners in younger age groups or the proportion of individuals with both-sex sexual experience. The results of both German studies agreed in the majority of analyses.

Median age of participants' first sexual contact in HaBIDS was 17 years in women and 18 years in men which is consistent with the median age of sexual debut in Natsal and $\mathrm{NSFG}^{7,8}$. Across all age groups, over three-fourths of participants in HaBIDS and Natsal maintained a stable opposite-sex sexual relationship in the last 12 months. The only exceptions were those below 25 years where almost half of the study population in both studies reported one or more new opposite-sex sexual partners. This is not unexpected as research has previously demonstrated that adolescents are more likely than adults to report multiple sex partners in the recent past ${ }^{18,19}$. German studies showed a lower number of lifetime sexual partners than Natsal and NSFG. This pattern was driven by a higher proportion of individuals with a high number of partners in the younger age groups in the UK and US. The observed differences have potentially huge implications for the way infectious diseases spread in the respective societies, since high activity groups are at the core of transmission.

Less than $10 \%$ of all participants reported to have ever had a same-sex sexual relationship in all studies across all age groups; among those with experience with sexual partners from both sexes the number of lifetime sexual partners was considerably lower in HaBIDS than in the other studies. This is especially important because this subpopulation serves as a bridging population in diseases where transmission dynamics are different among opposite-sex and same-sex partnerships.

\section{Strengths and limitations}


Even though the four surveys were conducted independently with different setups, they sought the same information. Nevertheless, questions used in the four surveys differed slightly from each other opening the chance for misclassification.

Some of the differences observed between studies might have occurred because of differences in sampling techniques, survey aims, or the longevity of projects associated with surveys. More sexual partners were reported in the UK which could be attributed to Natsal's long-term research on sexual contacts, so that study participants were aware and familiar with Natsal and less likely to report lower numbers of partner because of societal norms. On the contrary, HaBIDS was not purely designed to focus on sexual behaviour but evaluated in more general terms knowledge, attitudes, and practice related to infectious diseases so that participants might have felt less comfortable and might have underreported the true number of sexual partners.

The data were cross-sectional, so that comparisons across age are also comparisons of different cohorts. Nevertheless, the observed patterns across age appeared consistent with stable partner change behaviour in the last few decades.

The long-term panel nature of HaBIDS resulted in a much lower response proportion (9\%) compared with SBG (52\%), Natsal (58\%) and NSFG (77\%); while willingness to participate in studies generally decreases, the lower response proportion could be a potential source of bias e.g. because individuals with university degrees were more likely to participate resulting in an overestimation in HaBIDS, and tend to differ in their sexual contact patterns from individuals without university degrees. In all the four studies, participants filled in questionnaires by themselves without interviewers. While this provided more privacy, it is still possible that respondents deliberately chose not to divulge correct information. Moreover, respondents might not have recalled information correctly, particularly if the numbers were high. In case of difficulties to recall, partnerships in the past 12 months may be the most reliable measure ${ }^{20}$. Given that these points affected all studies equally, it is unlikely that they were responsible for observed differences between studies.

\section{Conclusion}

In both German studies, there was a lower proportion of participants with a high number of partners in younger age groups when compared to Natsal and NSFG. This resulted in a lower number of lifetime partners also at older ages, even if the partner acquisition above 24 years was similar in all studied populations. Dependent on the characteristics of the studied sexually transmitted infections, these patterns can lead to substantially different prevalences and incidences of sexually transmitted infections across age, and have strong impact on modelling studies of potential interventions (e.g. vaccination or screening effects).

\section{Declarations}


Acknowledgments

We thank Prof. Dr. phil. Christoph Kröger (SBG), the team members of Natsal-3 (Nastal) and the National Center for Health Statistics (NSFG) for providing data for the analyses of this study.

\section{Author contributions}

N.R., A.K., and R.M. designed the HaBIDS study, D.V.T., V.K.J., S.K.B., N.R., and J.H. conducted the statistical analyses, D.V.T., V.K.J., A.K., and R.M. wrote the manuscript. All authors interpreted the study findings, contributed to the manuscript, and approved the final version of the manuscript.

\section{Additional Information}

The authors declare no competing interests.

\section{Data availability}

HaBIDS datasets are available from the authors upon valid scientific request. For other studies datasets, please contact SBG, Natsal and NSFG authors respectively.

\section{References}

1. WHO Department of Reproductive Health and Research. Report on global sexually transmitted infection surveillance, 2018. World Health Organization (2018).

2. Hughes, G. \& Field, N. The epidemiology of sexually transmitted infections in the UK: Impact of behavior, services and interventions. Future Microbiol. 10, 35-51 (2015).

3. Aral, S. O., Over, M., Manhart, L. \& Holmes, K. K. Disease Control Priorities in Developing Countries, Chapter 17: Sexually transmitted infections. 311-330 (2006).

4. Mabey, D. Epidemiology of sexually transmitted infections: Worldwide. Med. (United Kingdom) 42, 287-290 (2014).

5. Díaz, A. \& Díez, M. Infecciones de transmisión sexual: epidemiología y control. Rev. Española Sanid. Penit. 13, 58-66 (2011).

6. Lurie, M. N. \& Rosenthal, S. Concurrent partnerships as a driver of the HIV epidemic in sub-saharan Africa? The evidence is limited. AIDS Behav. 14, 17-24 (2010).

7. Mercer, C. H. et al. Changes in sexual attitudes and lifestyles in Britain through the life course and over time: Findings from the National Surveys of Sexual Attitudes and Lifestyles (Natsal). Lancet 382, 1781-1794 (2013).

8. Lepkowski, J. M., Mosher, W. D., Davis, K. E., Groves, R. M. \& Van Hoewyk, J. The 2006-2010 National Survey of Family Growth: sample design and analysis of a continuous survey. Vital Health Stat. 2. 136 (2010). 
9. Chandra, A., Mosher, W. D., Copen, C. \& Sionean, C. Sexual behavior, sexual attraction, and sexual identity in the united states: Data from the 2006-2008 national survey of family growth. Sex. Stat. Sel. Reports from Natl. Cent. Heal. Stat. 19, 1-74 (2013).

10. Rübsamen, N., Akmatov, M. K., Castell, S., Karch, A. \& Mikolajczyk, R. T. Comparison of response patterns in different survey designs: a longitudinal panel with mixed-mode and online-only design. Emerg. Themes Epidemiol. 14, 1-11 (2017).

11. Rübsamen, N., Akmatov, M. K., Castell, S., Karch, A. \& Mikolajczyk, R. T. Factors associated with attrition in a longitudinal online study: Results from the HaBIDS panel. BMC Med. Res. Methodol. 17, 1-11 (2017).

12. Rübsamen, N. et al. Ebola Risk Perception in Germany, 2014. Emerg. Infect. Dis. 21, (2015).

13. Haversath, J. et al. Sexual behavior in Germany - Results of a representative survey. Dtsch. Arztebl. Int. 114, 545-550 (2017).

14. Lepkowski, J. M. et al. Responsive design, weighting, and variance estimation in the 2006-2010 national survey of family growth. Vital and Health Statistics, Series 2: Data Evaluation and Methods Research (2013).

15. Team, R. C. A language and environment for statistical computing. R Foundation for Statistical Computing. (2019).

16. Wickham, H. ggplot2: Elegant Graphics for Data Analysis. (Springer-Verlag New York, 2016).

17. Brian Ripley [aut, cre, C. et al. Modern Applied Statistics with S. (2002) doi:ISBN 0-387-95457-0.

18. Santelli, J. S., Brener, N. D., Lowry, R., Bhatt, A. \& Zabin, L. S. Multiple sexual partners among U.S. Adolescents and young adults. Fam. Plann. Perspect. 30, 271-275 (1998).

19. Durbin, M. et al. Factors associated with multiple sex partners among junior high school students. $J$. Adolesc. Heal. 14, 202-207 (1993).

20. Todd, J. et al. Reported number of sexual partners: Comparison of data from four African longitudinal studies. Sex. Transm. Infect. 85, (2009).

\section{Figures}


a) HaBIDS

造

$100 \%$

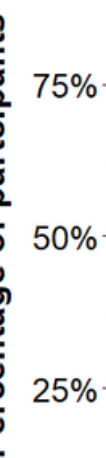

$0 \%$ b) Natsal

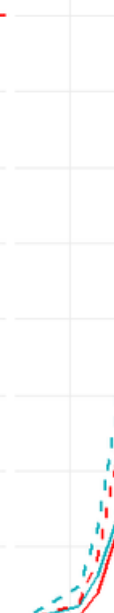

c) NSFG

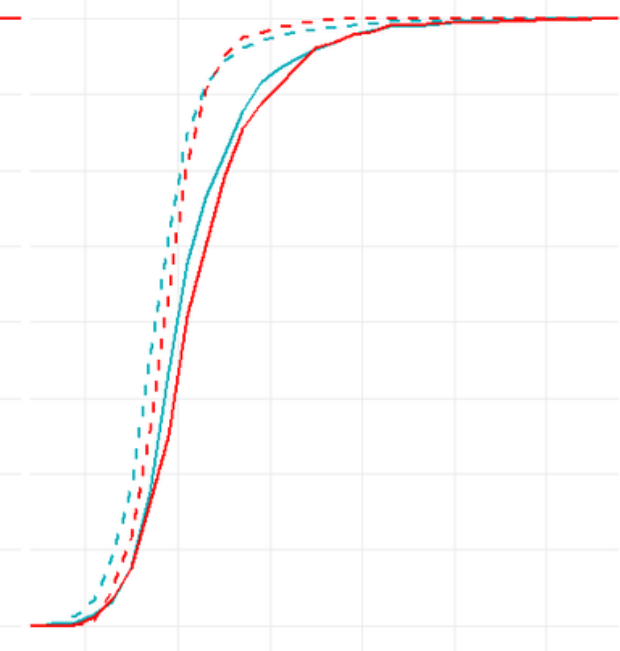

\section{Participant's age of first sexual contact (in years)}

- Men with university qualifications, HaBIDS $(N=204)$, Natsal $(N=1430)$, NSFG (481)

- Men without university qualifications, HaBIDS ( $N=213)$, Natsal $(N=4277)$, NSFG (702)

- Women with university qualifications, $\operatorname{HaBIDS}(N=268)$, Natsal $(N=2001)$, NSFG (434)

- Women without university qualifications, HaBIDS $(\mathrm{N}=458)$, Natsal $(\mathrm{N}=6212)$, NSFG (542)

\section{Figure 1}

Participants' age of their first sexual contact stratified by education and sex between studies (visualised as a cumulative percentage) for (a) HaBIDS (b) Natsal (c) NSFG Note: this information was only available for about $10 \%$ of NSFG participants 


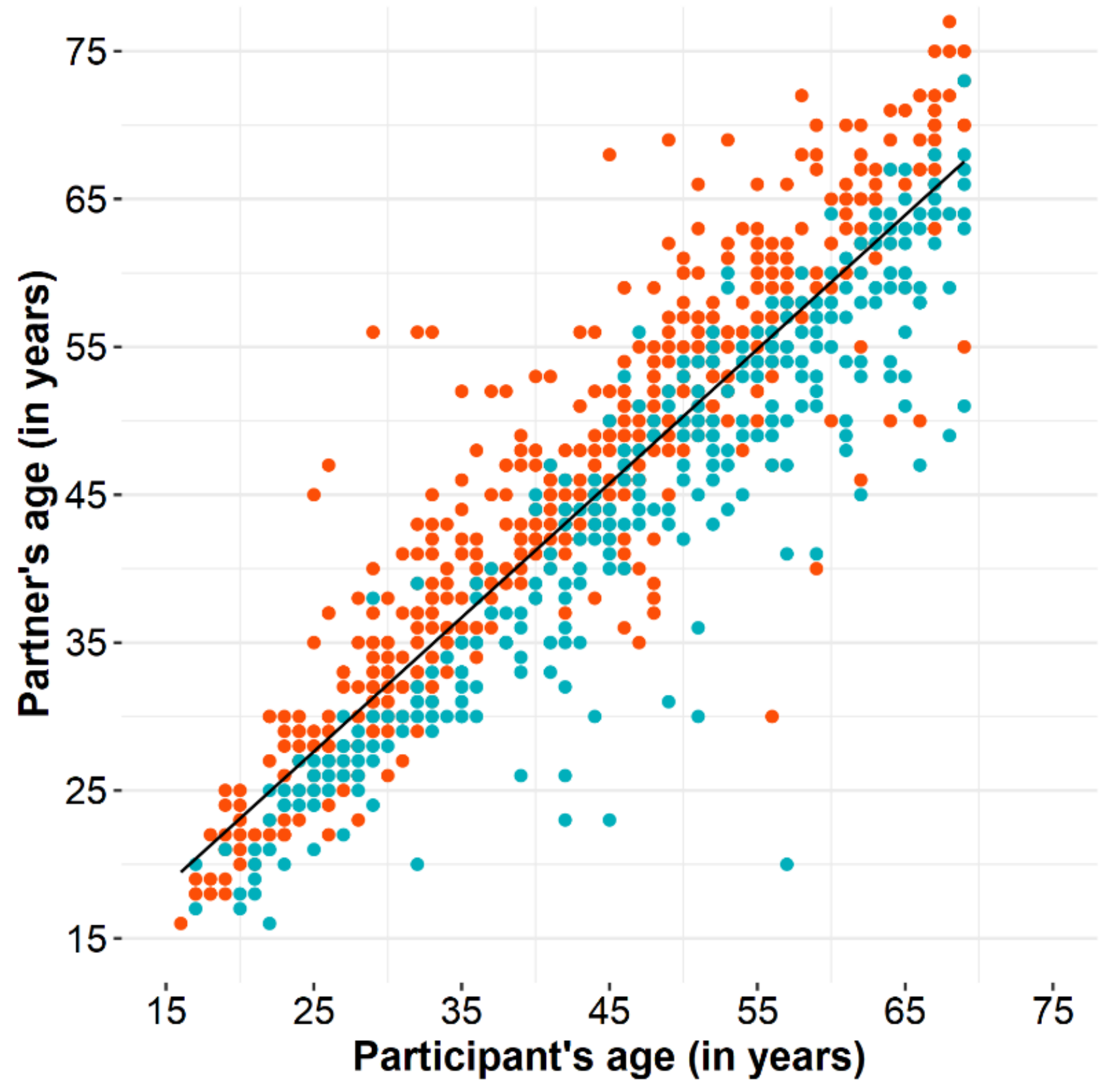

- Women; Men as partner, $\mathrm{N}=575$

- Men; Women as partner, $\mathrm{N}=327$

Figure 2

Participants' age and the age of their current partners in HaBIDS 
a)

Opposite-sex sexual partners in the participant's entire life

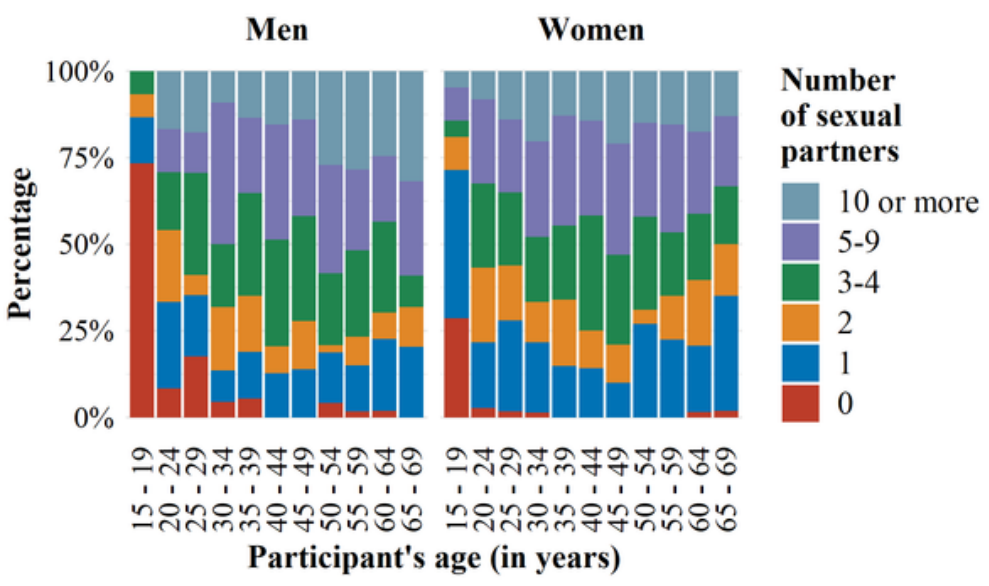

b)

Opposite-sex sexual partners in the last 12 months (based on rticipants who had at least one lifetime opposite-sex sexual partner)

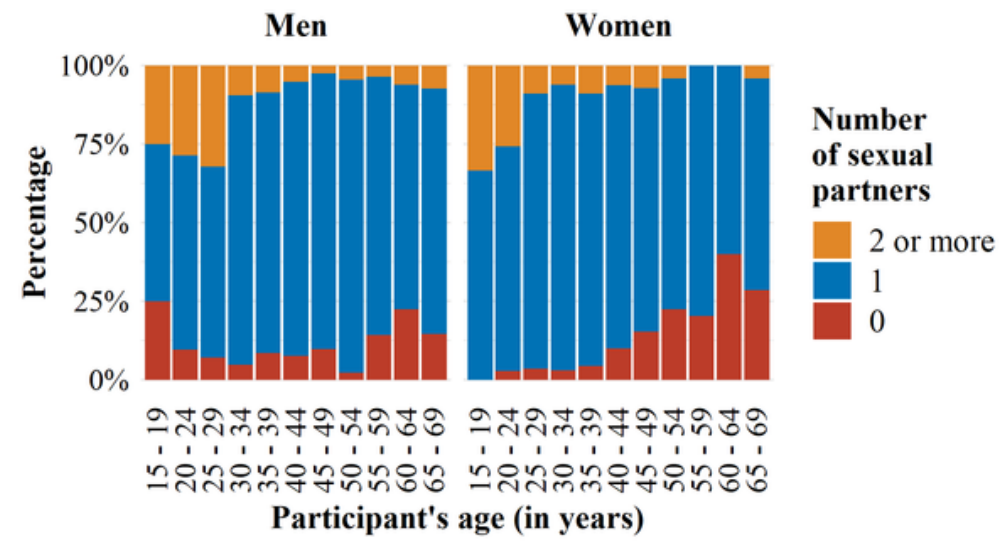

c)

New opposite-sex sexual partners in the last 12 months (based on participants who had at least one opposite-sex sexual partner in the last 12 months)

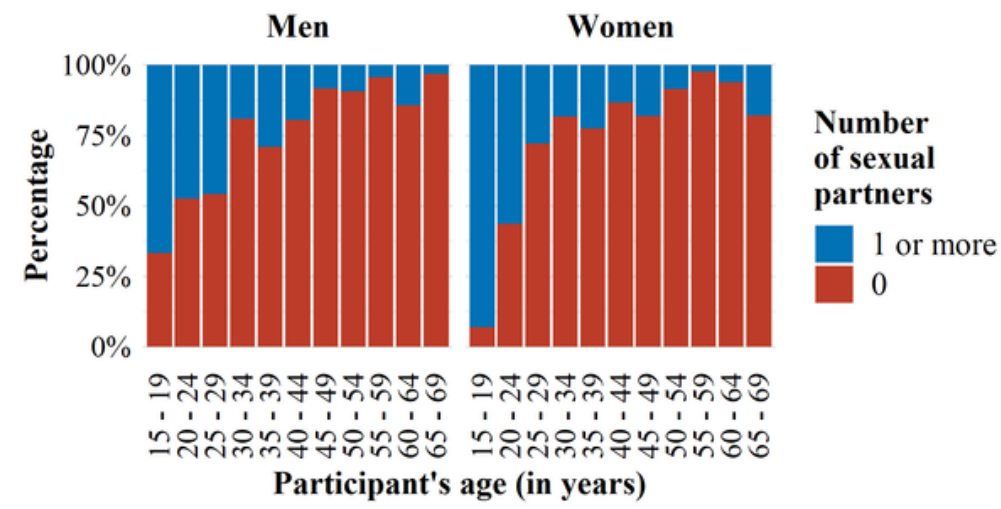

Figure 3

Number of opposite-sex sexual partners in HaBIDS participants stratified by sex (a) in the participants' entire life (b) in the last 12 months (based on participants who had at least one lifetime opposite-sex sexual partner) and (c) new opposite-sex sexual partners in the last 12 months (based on participants who had at least one opposite-sex sexual partner in the last 12 months) 

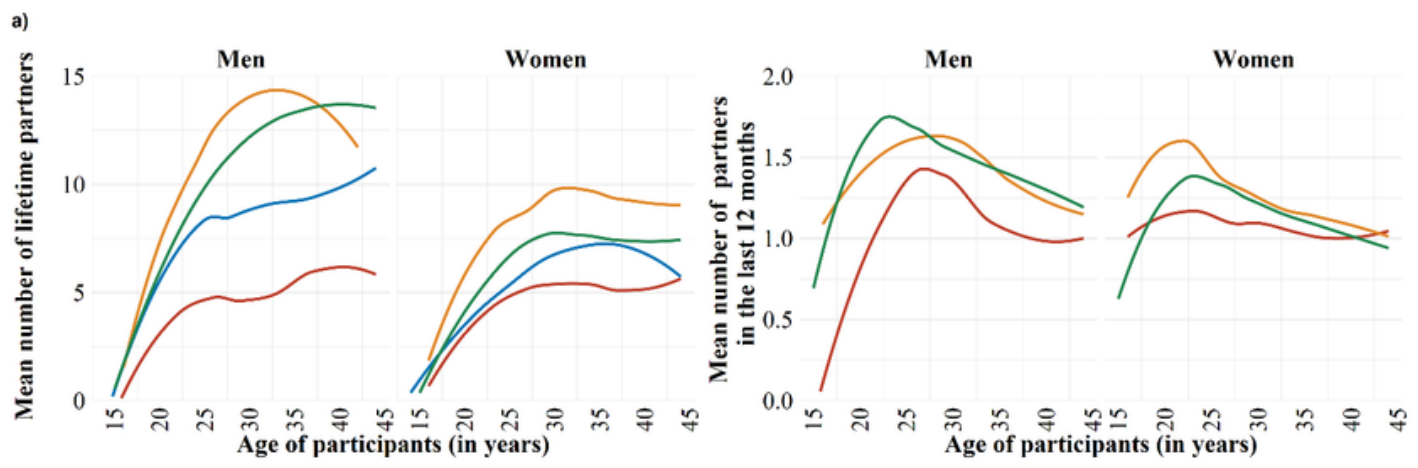

- HaBIDS - SBG - Natsal - NSFG

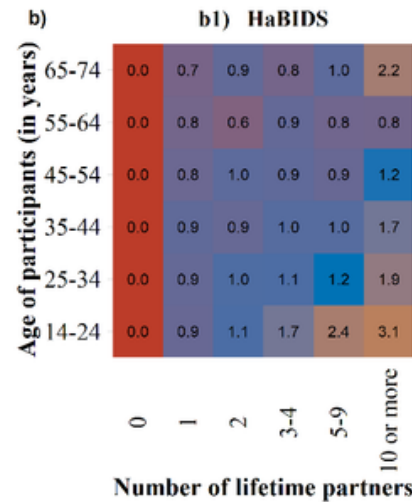

c)

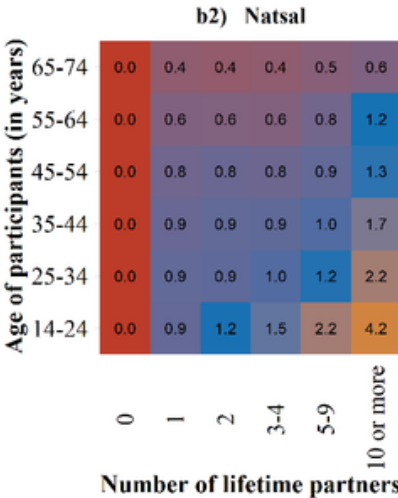

b3) NSFG

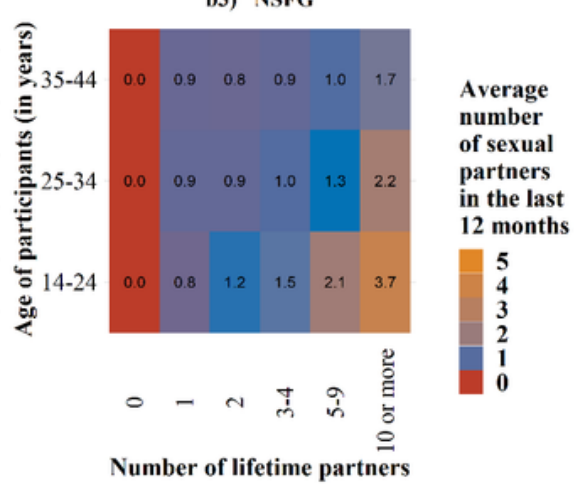

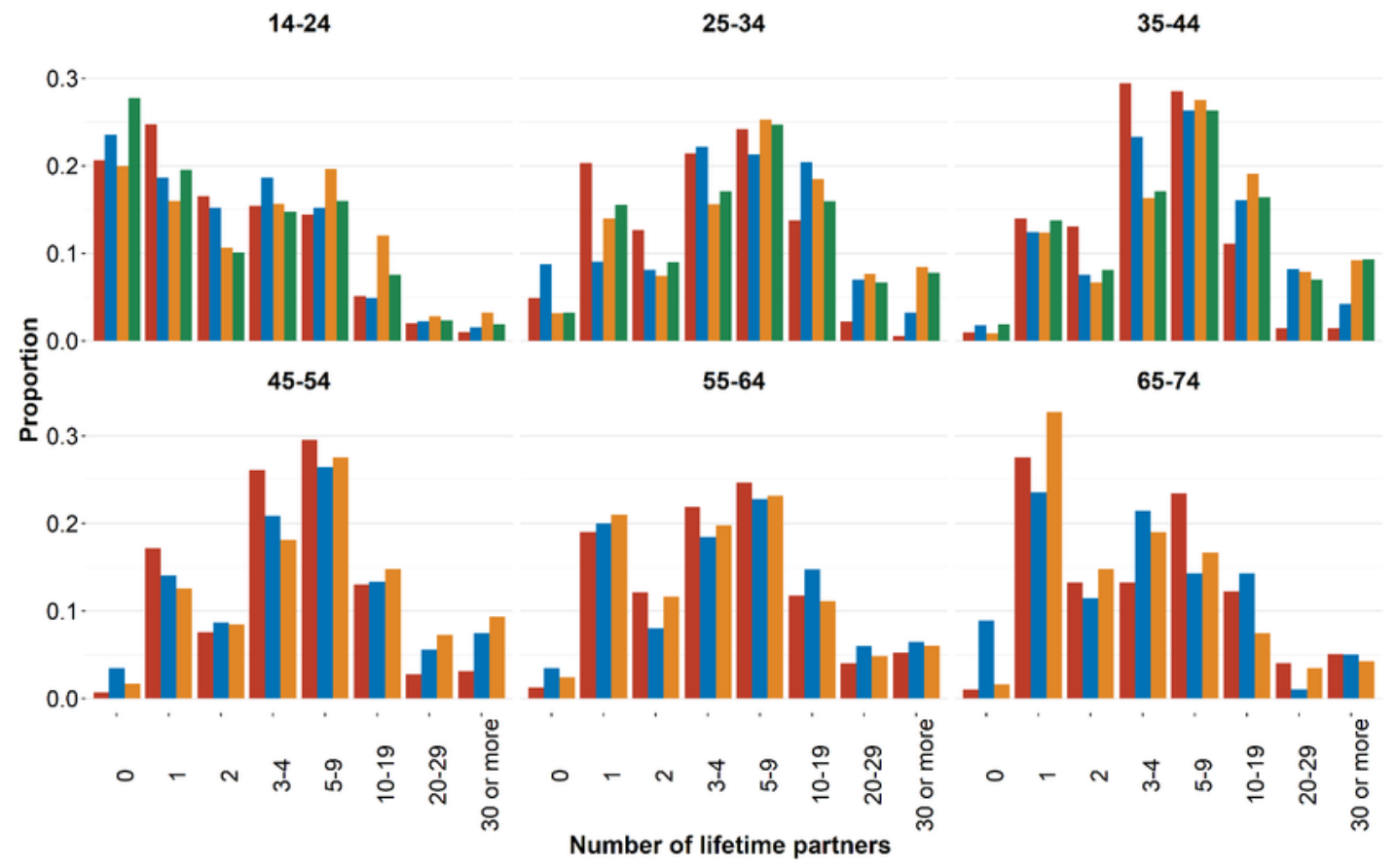

$\square$ HaBIDS $\square$ SBG $\square$ Natsal $\square$ NSFG

\section{Figure 4}

Comparison between studies on (a) the mean number of reported opposite-sex sexual partners by age in lifetime and in the last 12 months: (b) mean number of opposite-sex sexual partners in the last 12 months by age and lifetime partners; and (c) proportion of lifetime partners across age groups 


\section{Same-sex sexual partners among participant's who had at least one same-sex lifetime sexual partner}

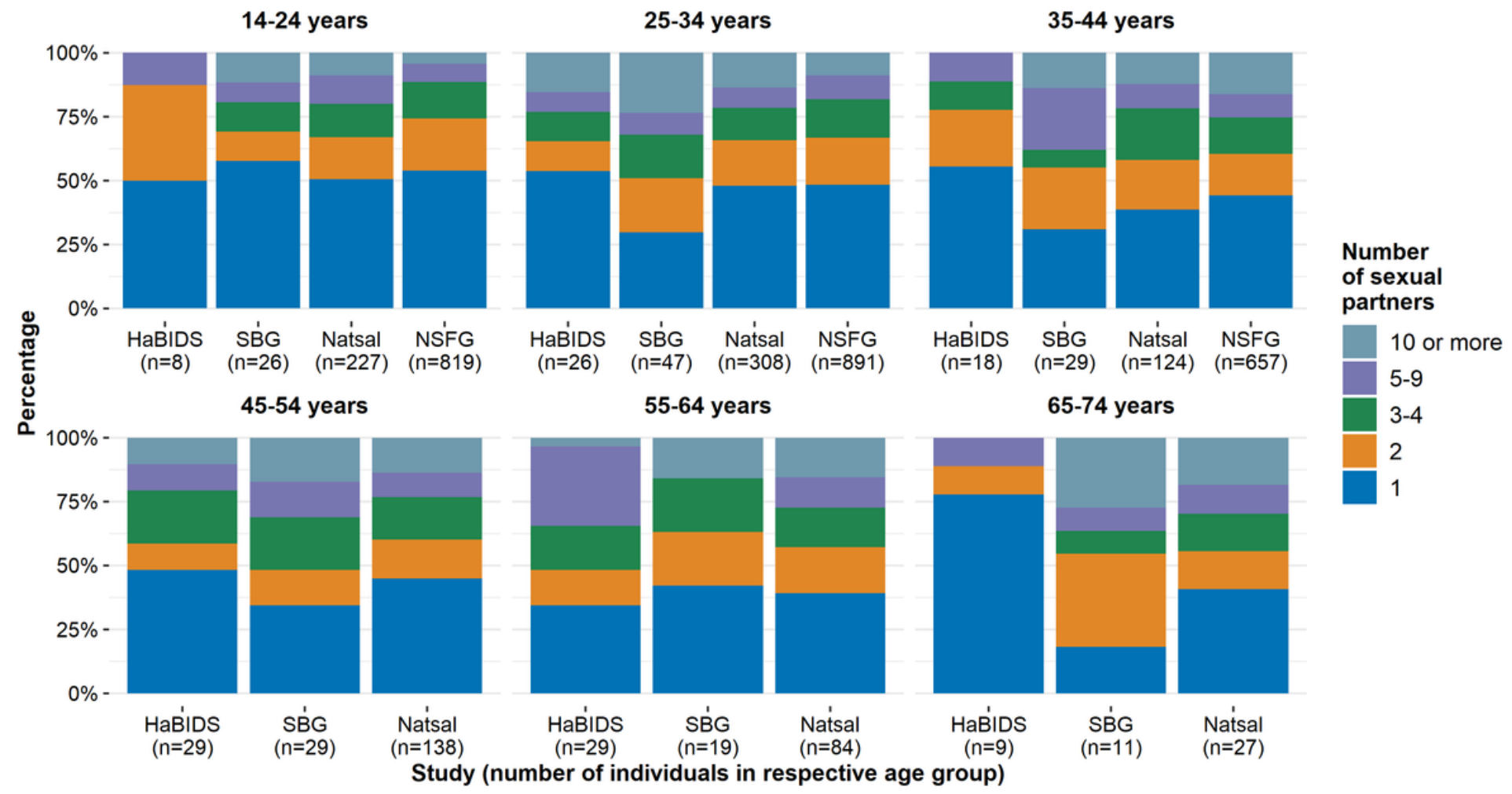

\section{Figure 5}

Comparison between studies on those who reported to have had at least one same-sex lifetime sexual partner categorized by age.

\section{Supplementary Files}

This is a list of supplementary files associated with this preprint. Click to download.

- SuppementaryFile.pdf 